\title{
PERCEPÇÃO DOS CONSUMIDORES DE PROTEÍNA ANIMAL SOBRE O BEM- ESTAR DOS ANIMAIS DE PRODUÇÃO NO MUNICIPIO DE PARAUAPEBAS, PARÁ, BRASIL
}

\author{
Meyse Leal de Abreu ${ }^{1}$ \\ Gabriel da Silva Dantas ${ }^{1}$ \\ Welligton Conceição da Silva ${ }^{2}$ \\ Antônio Vinicius Corrêa Barbosa ${ }^{1}$ \\ Jamile Andréa Rodrigues da Silva ${ }^{1}$
}

\begin{abstract}
RESUMO
Objetivou-se avaliar o nível de conhecimento dos consumidores de produtos de origem animal a respeito do bem-estar dos animais de produção, na cidade de Parauapebas-Pará, Brasil. Foram aplicados questionários contendo dez questões relacionadas ao tema bem-estar animal, totalizando 342 entrevistados, escolhidos de forma aleatória, considerando-se quatro perguntas de cunho socioeconômico, cujos entrevistados foram organizados em seis níveis educacionais e cinco níveis de renda familiar. A pesquisa foi realizada em feiras, açougues, mini mercados e duas grandes redes de supermercados da cidade de Parauapebas, em bairros diferentes, para abranger público com níveis distintos de renda e que de estivessem, de preferência, consumindo ou adquirindo produtos de origem animal. Os dados coletados foram analisados por teste não paramétrico de significância a 5\%. Percebeu-se que os consumidores com melhor nível de escolaridade e com renda mais elevada estão dispostos a pagar por um produto de melhor qualidade e durabilidade e acreditam que com o avanço do conhecimento em relação ao bem-estar os produtos certificados passaram a ser mais acessível a consumidores menos favorecidos.
\end{abstract}

PALAVRAS-CHAVE. alimento, certificação de qualidade, consumidor.

\section{PERCEPTION OF ANIMAL PROTEIN CONSUMERS ON THE STATE OF PRODUCTION ANIMALS IN THE CITY OF PARAUAPEBAS, PARÁ, BRAZIL}

\begin{abstract}
The objective was to assess the level of knowledge of consumers of products of animal origin regarding the welfare of farm animals, in the city of Parauapebas-Pará, Brazil. Questionnaires containing ten questions related to the theme of animal welfare were applied, totaling 342 respondents, chosen at random, considering four questions of a socioeconomic nature, whose respondents were organized into six educational levels and five levels of family income. The research was carried out in fairs, butchers, mini markets and two large supermarket chains in the city of Parauapebas, in different neighborhoods, to reach audiences with different levels of income and who were, preferably, consuming or purchasing products of animal origin. The collected data were analyzed by a non-parametric test of significance at $5 \%$. It was noticed that consumers with better education and higher income are willing to pay for a product of better quality and durability and believe that with the advance of knowledge in relation to well-being, certified products have become more accessible less favored consumers.
\end{abstract}

KEY WORDS. food, quality certification, consumer.

${ }^{1}$ UFRA leal.zootecnia@gmail.com

${ }^{2}$ UFRA. Correspondência welligton.medvet@gmail.com

Abreu ML, Dantas GS, Silva WC, Barbosa AVC, Silva JAR. Percepção dos consumidores de proteína animal sobre o bem-estar dos animais de produção no município de Parauapebas, Pará, Brasil. Vet. e Zootec. 2021; 28: 001-012. 


\title{
PERCEPCIÓN DE CONSUMIDORES DE PROTEÍNA ANIMAL SOBRE EL BIENESTAR DE LOS ANIMALES DE PRODUCCIÓN EM LA CIUDAD DE PARAUAPEBAS, PARÁ, BRASIL
}

\begin{abstract}
RESUMEN
El objetivo fue evaluar el nivel de conocimiento de los consumidores de productos de origen animal con respecto al bienestar de los animales de granja, en la ciudad de Parauapebas-Pará, Brasil. Se aplicaron cuestionarios que contenían diez preguntas relacionadas con el tema bienestar animal, con un total de 342 encuestados, elegidos al azar, considerando cuatro preguntas de naturaleza socioeconómica, cuyos encuestados se organizaron en seis niveles educativos y cinco niveles de ingresos familiares. La investigación se llevó a cabo en ferias, carnicerías, mini mercados y dos grandes cadenas de supermercados en la ciudad de Parauapebas, en diferentes barrios, para llegar a audiencias con diferentes niveles de ingresos y que, preferiblemente, consumían o compraban productos de origen animal. Los datos recopilados se analizaron mediante una prueba no paramétrica de significancia al $5 \%$. Se observó que los consumidores con una mejor educación y mayores ingresos están dispuestos a pagar por un producto de mejor calidad y durabilidad y creen que con el avance del conocimiento en relación con el bienestar, los productos certificados se han vuelto más accesibles consumidores menos favorecidos.
\end{abstract}

PALAVRAS CLAVES. alimentación, certificación de calidad, consumidor.

\section{INTRODUÇÃO}

O bem-estar animal (BEA) é um tema mundialmente discutido e atualmente tem despertado interesse por parte da sociedade Brasileira. Em alguns países, as pesquisas sobre a percepção do consumidor quanto ao BEA e os impactos que o assunto representa sobre a alimentação humana podem influenciar no momento da compra. A carne de animais criados de acordo com a legislação de bem-estar é classificada pelos consumidores como um produto de melhor qualidade diferenciando-se dos produtos de animais criados intensivamente (1).

Os países que tradicionalmente exportam animais têm incorporado diferentes aspectos do BEA em suas práticas e regulamentações. Em algumas sociedades é observada a redução da aceitação de produtos de baixo preço, à custa do sofrimento e da exploração animal. Consumidores com maiores níveis de interesse sobre bem-estar animal, de acordo com a renda, estão dispostos pagar a mais pelos produtos oriundos dos sistemas de produção projetados com atenção às considerações da legislação. Além disso, a conscientização do consumidor quanto ao BEA também pode gerar efeitos negativos sobre o volume de vendas do POA nas grandes redes de supermercados (2).

Enquanto na Europa o tema do BEA é debatido há muitos anos, no Brasil o início da discussão é mais recente. Atualmente a legislação brasileira busca se adequar às recomendações internacionais de BEA, enquanto no meio acadêmico o tema vem sendo incluído e discutido em simpósios, congressos e em escolas de graduação e pós-graduação de medicina veterinária e zootecnia (3).

Acredita-se que uma rápida mudança na percepção do público quanto ao tratamento dos animais de produção na indústria alimentar pode influenciar na qualidade final e na escolha do produto de origem animal. Perante a necessidade de saber de que forma o consumidor paraense preocupa-se com o que consome e de expandir o tema, abordando consumidores de outras regiões do estado. Nesse sentido, este trabalho teve por objetivo avaliar o que os 
consumidores do município de Parauapebas, Pará, Brasil, julgam sobre a importância do bemestar dos animais de produção e de que forma o conhecimento sobre o assunto pode afetar na escolha e na compra de alimentos com certificação.

\section{MATERIAL E MÉTODOS}

O experimento foi conduzido no Município de Parauapebas, no sudeste do Pará, Brasil. A cidade possui atualmente em torno de 202.356 habitantes. No local, há presença de uma empresa mineradora de extração do minério de ferro que representa, até hoje, a principal fonte de recursos do Município, e chega a empregar cerca de 8.000 pessoas diretamente, e aproximadamente 20.000, indiretamente. Isso fez com que a cidade crescesse em torno das economias geradas por esse setor e dessa forma, outras empresas, comerciantes e grandes redes de supermercados despertaram interesses em expandir os negócios do local. A atividade agrícola no Município de Parauapebas, principalmente a pecuária, é pouco expressiva e os produtos agrícolas com maior participação no produto interno bruto do município são abacaxi, tomate e mandioca, com rendimento de cerca de 20.000 .000 de reais por ano cada.

Foi aplicado um questionário, contendo dez questões relacionadas ao tema bem-estar animal, totalizando 342 entrevistados, escolhidos de forma aleatória, considerando-se quatro perguntas de cunho socioeconômico, cujos entrevistados foram organizados em seis níveis educacionais e cinco níveis de renda familiar. A pesquisa foi realizada em feiras, açougues, mini mercados e duas grandes redes de supermercados da cidade de Parauapebas, em bairros diferentes, para abranger público com níveis distintos de renda e que de estivessem, de preferência, consumindo ou adquirindo produtos de origem animal. A hipótese experimental a ser testada foi que à condição financeira e o nível de informação sobre os produtos de origem animal (POA) pode estar relacionado com o interesse dos consumidores sobre BEA. Foi feita classificação socioeconômica, com base em dados do Instituto Brasileiro de Geografia e Estatística (4), ordenadas de acordo com o número de salários mínimos mensais conforme o Quadro 1.

Quadro 1. Classificação socioeconômica (IBGE).

\begin{tabular}{|c|c|}
\hline Classificação econômica & Faixa salarial (salário mínimo) \\
\hline A & $>15$ \\
B & $<15$ \\
C & 3 a 5 \\
D & 1 a 3 \\
E & $<1$ \\
\hline
\end{tabular}

Fonte: IBGE, 2016.

O questionário continha as seguintes perguntas, com respostas objetivas (sim ou não): 1 . Os produtos de origem animal fazem parte de sua dieta diária? 2. Você sabe como os animais que originam os produtos que você consome são criados? 3. Você se preocupa em saber quais são os métodos utilizados para criação ou abate dos animais? 4. Você já ouviu falar em bemestar animal? 5. Você acha que animais criados sob as normas de bem-estar originarão produtos de maior qualidade? 6 . Você pagaria mais por um produto para obter a garantia de que os animais foram criados sob condições de bem-estar? 7. Você acha que os animais de produção são submetidos a algum tipo de sofrimento durante sua criação? 8. Você sabe que existem leis que asseguram o bem-estar animal? 9. Você passaria a escolher produtos certificados (selos) por agências controladoras do bem-estar animal? 10. Você gostaria que as sobre o bem-estar dos animais de produção no município de Parauapebas, Pará, Brasil. Vet. e Zootec. 2021; 28: 001-012. 
redes de supermercado oferecessem produtos originados de acordo com as normas de bemestar?

Para a análise estatística, a pesquisa foi de natureza qualitativa nominal dicotômica. As respostas socioeconômicas e as respostas sobre bem-estar obtidas foram analisadas em percentagem, de forma individual pelo Analyze-Descriptive Statisctis-Crosstabs, através do software estatístico de análise preditiva (SPSS). As perguntas foram analisadas com teste não paramétrico de significância, através do teste de Person qui-quadrado $\left(x^{2}\right)$ ou teste de Fisher, quando o p-valor for maior que $20 \%$. O valor do qui-quadrado pode ser calculado usando a seguinte fórmula Levin (5):

$$
\chi^{2}=\Sigma[(f o-f e) 2 / f e]
$$

Onde: $x^{2}$ é o qui-quadrado; $f o$ é a frequência observada para cada classe; $f e$ é a frequência esperada para cada classe.

Para as frequências esperadas teóricas (fe) o cálculo pela seguinte fórmula:

$$
\text { fo:(total marginal "linha"). (total marginal "coluna") }
$$

Onde: fo é a frequência observada pela classe; $\boldsymbol{N}$ é o número total de sujeitos.

Para interpretação do resultado do qui-quadrado foi necessário determinar o número de graus de liberdade como:

$$
g l=(1-1) \cdot(c-1)
$$

Onde: $\boldsymbol{g} \boldsymbol{l}$ é o número de graus de liberdade e $\boldsymbol{l}$ é o número de linhas na tabela de frequências observadas; $c$ é o número de colunas na tabela de frequências observadas.

Sendo a matriz de contingência composta por duas linhas e duas colunas $(2 \times 2)$, com graus de liberdade iguais a 1. Dessa forma, o valor crítico do qui-quadrado, em nível de significância de 5\% é de 3,84. Para que a hipótese experimental seja aceita, o valor do quiquadrado deve ser igual ou superior a 3,84 .

\section{RESULTADOS E DISCUSSÃO}

Ao analisar o perfil de cada entrevistado, constatou-se que, 49,7\% (170/342) são mulheres, e dessas, 95,9\% (163/170) consomem produtos de origem animal. Observou-se também que 50,3\% (172/342) eram homens, e desses, todos consomem produtos de origem animal. Apenas 2,0\% não consumiam produtos de origem animal, sendo eles todos do sexo feminino. Essa pequena diferença pode estar relacionada ao modo de vida e/ou mudanças de hábito alimentar já que os $2 \%$ que não consumiam POA possuíam renda acima de 1 a 3 salários mínimos e cursavam ou já possuíam curso superior completo.

As informações sócio-econômicas dos tutores, tais quais, escolaridade, faixa etária e renda familiar são fatores que podem ser determinantes para a percepção de bem-estar em animais de produção. Quanto à faixa etária dos consumidores entrevistados na presente pesquisa, constatou-se que o maior percentual $(46,5 \%)$ tem idade entre 18 a 30 anos (Tabela $1)$.

Abreu ML, Dantas GS, Silva WC, Barbosa AVC, Silva JAR. Percepção dos consumidores de proteína animal sobre o bem-estar dos animais de produção no município de Parauapebas, Pará, Brasil. Vet. e Zootec. 2021; 28: 001-012. 
Na Tabela 2 observam-se os índices de escolaridade dos entrevistados. A maioria dos consumidores possui ensino médio completo, muita deles fizeram cursos técnicos, o que indica que, provavelmente essas pessoas teriam conhecimento básico sobre o assunto.

Tabela 1. Faixa etária dos consumidores de produtos de origem animal, em Parauapebas, Pará, Brasil.

\begin{tabular}{ccc}
\hline Faixa etária & Frequência & Percentual (\%) \\
\hline $18-30$ anos & 159 & 46,5 \\
$30-40$ anos & 97 & 28,4 \\
$40-50$ anos & 52 & 15,5 \\
$50-60$ anos & 25 & 7,3 \\
$>60$ anos & 92 & 6 \\
\hline Total & 342 & 100 \\
\hline
\end{tabular}

Tabela 2. Índice de escolaridade de consumidores de produtos de origem animal, em Parauapebas, Pará, Brasil.

\begin{tabular}{ccc}
\hline Níveis de escolaridade & Frequência & Percentual (\%) \\
\hline Ensino fundamental incompleto & 21 & 6,1 \\
Ensino fundamental completo & 22 & 6,4 \\
Ensino médio incompleto & 29 & 8,5 \\
Ensino médio completo & 154 & 44,5 \\
Ensino superior incompleto & 61 & 17,8 \\
Ensino superior completo & 55 & 16,1 \\
\hline Total & 342 & 100 \\
\hline
\end{tabular}

Com relação à renda familiar, observou-se que a maioria das pessoas recebem de 1 a 3 salários mínimos (56,7\%), conforme observado na Tabela 3.

Tabela 3. Renda média familiar dos de consumidores de produtos de origem animal, em Parauapebas, Pará, Brasil.

\begin{tabular}{ccc}
\hline Faixa de renda & Frequência & Percentual (\%) \\
\hline 1-3 salários mínimos & 194 & 56,7 \\
3-6 salários mínimos & 106 & 31 \\
6-9 salários mínimos & 28 & 8,2 \\
9-12 salários mínimos & 14 & 4,1 \\
$>$ 12 salários mínimos & 00 & 00 \\
\hline Total & 342 & 100 \\
\hline
\end{tabular}

Quanto ao conhecimento a respeito do modo de criação dos animais de produção, observou-se que 56,7\% (197/342) das pessoas já visitaram alguma propriedade e, portanto, conhecem como os animais de produção são criados e somente 50,9\% (174/342) dos entrevistados conhecem os métodos de abate dos animais de produção. Em Curitiba, Paraná, Bonamigo et al. (6) constataram que 68,5\% dos entrevistados não conhecem os sistemas de produção animal. Estes resultados são preocupantes para que ocorram modificações nos sistemas produtivos, pois a falta de informação é a maior barreira para a aquisição e consumo de produtos diferenciados em termos de bem-estar (7).

Em relação ao conhecimento sobre como os animais que originam os produtos são criados, se com bem-estar ou não, 64\% (219/342) das pessoas afirmaram saber, sendo que $52,1 \%$ eram homens. Dos 342 consumidores entrevistados, 43,3\% nunca tiveram contato com animais de produção, entretanto, 56,7\% deles disseram conhecer os sistemas de produção Abreu ML, Dantas GS, Silva WC, Barbosa AVC, Silva JAR. Percepção dos consumidores de proteína animal sobre o bem-estar dos animais de produção no município de Parauapebas, Pará, Brasil. Vet. e Zootec. 2021; 28: 001-012. 
animal, mesmo que parcialmente. Segundo Schaly et al. (1), há evidências que sugerem que pessoas que já visitaram uma fazenda são mais prováveis de considerar o bem-estar como um fator importante no momento da compra de produtos de origem animal.

Sobre o método de abate dos animais, grande parte, 50,9\% (174/372), afirmaram que conhecem, mesmo que superficialmente, sobre os procedimentos de abate, embora $49,1 \%$ dos consumidores não se interessa sobre o abate de animais. Esses resultados estão de acordo com os observados por Pinheiro et al. (8) que observaram que a maioria dos consumidores $(63,78 \%)$ gostariam de saber a origem da carne bovina que compram, em Boa Vista, Roraima. Em pesquisa realizada em Araucária, Paraná, Pedrazzani et al. (9) observaram grande interesse dos entrevistados pelo assunto, o que demonstra a preocupação com o método de abate nos frigoríficos, o que resultaria em diferencial para o mercado consumidor.

A maioria dos consumidores $(64 \%)$ ouviu falar ou tem algum conhecimento sobre o tema bem-estar animal (BEA) e 93,6\% acreditam que animais bem tratados originam produtos de melhor qualidade. Dos 342 consumidores entrevistados, 71,3\% afirmam que pagariam um pouco a mais por produtos certificados, com selo de bem-estar animal, 78,4\% acham que os animais sofrem durante o processo de criação e 45,3 \% (155/243) afirmam conhecer sobre as leis de bem-estar animal. Independente do preço, 89,5\% (306/342) das pessoas escolheriam produtos com certificação, e 95,6\% gostariam que os supermercados oferecessem produtos com selo de bem-estar animal. Segundo Molento (3), as sociedades têm tendência a ter preferências por produtos certificados, como resultado de educação e conhecimento de conceitos básicos de bem-estar animal.

Sobre a relação entre a faixa etária dos consumidores e a percepção sobre bem-estar em animais de produção (Tabela 4), 46,5\% tinham de 18 a 30 anos, 28,4\%, de 30 a 40 anos, $15,2 \%$ de 40 a 50 anos, $7,3 \%$ de 50 a 60 anos e 2,6 acima de 60 anos.

Tabela 4. Influência da faixa etária sobre a percepção de bem-estar em animais de produção, em Parauapebas, Pará, Brasil.

\begin{tabular}{cccccc}
\hline Perguntas & $\mathbf{1 8 - 3 0}$ anos & $\mathbf{3 0 - 4 0}$ anos & $\mathbf{4 0 - 5 0}$ anos & $\mathbf{5 0 - 6 0}$ anos & 60 ou mais \\
\hline 1 & $98,7 \%$ & $96,9 \%$ & $96,2 \%$ & $100 \%$ & $100 \%$ \\
2 & $59,7 \%$ & $55,2 \%$ & $51,9 \%$ & $52 \%$ & $55,6 \%$ \\
3 & $52,2 \%$ & $50,5 \%$ & $44,2 \%$ & $56,0 \%$ & $55,6 \%$ \\
4 & $63,5 \%$ & $62,9 \%$ & $59,6 \%$ & $76,0 \%$ & $77,8 \%$ \\
5 & $93,7 \%$ & $92,8 \%$ & $92,3 \%$ & $96,0 \%$ & $100 \%$ \\
6 & $71,1 \%$ & $78,4 \%$ & $69,2 \%$ & $60,0 \%$ & $44.4 \%$ \\
7 & $76,1 \%$ & $76,3 \%$ & $82,7 \%$ & $92,0 \%$ & $77,8 \%$ \\
8 & $43,4 \%$ & $49,5 \%$ & $32,7 \%$ & $68,0 \%$ & $44,4 \%$ \\
9 & $91,2 \%$ & $86,6 \%$ & $88,5 \%$ & $92,0 \%$ & $44,4 \%$ \\
10 & $96,9 \%$ & $95,9 \%$ & $94,2 \%$ & $88 \%$ & $100 \%$ \\
\hline
\end{tabular}

Observou-se que todos os entrevistados com idade acima de 50 anos afirmam que os produtos de origem animal fazem parte de sua dieta diária. E em todas as outras faixas etárias, os produtos de origem animal são rotina em suas dietas. Cerca de $50 \%$ dos entrevistados de todas as faixas etárias informaram que sabem como os animais que originam os produtos consomem são criados. Esse resultado pode estar relacionado ao fato de que, em Parauapebas, interior do Pará, Brasil, as pessoas têm mais contato com propriedades de produção animal, de alguma maneira. Da mesma forma, cerca da metade dos entrevistados de todas as faixas etárias se preocupam em saber quais são os métodos utilizados para criação ou abate dos animais, sendo que as pessoas com idade entre 40 e 50 anos, tiveram o menor percentual $(44,2 \%)$.

Abreu ML, Dantas GS, Silva WC, Barbosa AVC, Silva JAR. Percepção dos consumidores de proteína animal sobre o bem-estar dos animais de produção no município de Parauapebas, Pará, Brasil. Vet. e Zootec. 2021; 28: 001-012. 
Com relação ao termo "bem-estar animal", percebeu-se que os entrevistados acima de 50 anos são os que de alguma maneira já ouviram falar sobre o assunto e o sabem conceituar, com $76 \%$ das pessoas com idade entre 50 e 60 anos e $77,8 \%$ das pessoas acima de 60 anos de idade. Mais de $90 \%$ dos entrevistados de todas as faixas etárias acham que animais criados sob as normas de bem-estar originarão produtos de maior qualidade e houve maior percentual de pessoas com idade entre 18 e 30 , e de 30 a 40 anos que pagaria mais por um produto para obter a garantia de que os animais foram criados sob condições de bem-estar $(71,1$ e 78,4\%, respectivamente).

Grande parte das pessoas de todas as faixas etárias acham que os animais de produção são submetidos a algum tipo de sofrimento durante sua criação, destacando-se as pessoas com idade entre 50 e 60 anos, com $92 \%$. Para eles, isso somente se dá quando se trata de criações em grande escala como em granjas suinícolas e avícolas. Essas pessoas também sabem que existem leis que asseguram o bem-estar animal, com maior percentual (68\%).

A maioria das pessoas de todas as faixas etárias passaria a escolher produtos certificados (selos) por agências controladoras do bem-estar animal, exceto as pessoas com mais de 60 anos, pois somente $44,4 \%$ dessas pessoas escolheriam esses produtos. Da mesma forma, independente da faixa etária, grande parte dos entrevistados gostariam que as redes de supermercado oferecessem produtos originados de acordo com as normas de bem-estar. Um pequeno grupo de entrevistados acreditava que as leis de bem-estar somente eram aplicáveis a animais de companhia e foi observado que pessoas com mais idade não acreditavam que a certificação dos produtos garantiria uma qualidade de vida melhor aos animais de produção. Esses resultados contrastam com os observados em Porto Alegre, Rio Grande do Sul, onde há exigência dos consumidores por boa qualidade do produto, pois essas pessoas querem se certificar que estão consumindo alimentos bons para sua saúde, produzidos, processados e distribuídos por agentes confiáveis (10). Empresas ou cadeias produtivas orientadas para o consumidor obterão vantagens competitivas frente às demais, em virtude do ambiente concorrencial onde estão inseridas, pois, para que as empresas tenham sucesso, é importante saber o que o consumidor deseja (11).

O conhecimento sobre as questões éticas e de bem-estar pode também estar relacionado com o nível de escolaridade e de como essas pessoas estão recebendo esse tipo de informação. $\mathrm{Na}$ Tabela 5 verifica-se que $6,4 \%$ dos consumidores de produtos de origem animal, tinham cursado apenas o ensino fundamental, quase metade dos entrevistados (45\%) tinha apenas o ensino médio/técnico. Consumidores com níveis de escolaridade mais elevados têm maiores oportunidades de exigir informações sobre os sistemas de produção de animais para consumo humano (1).

Tabela 5. Influência da escolaridade de consumidores sobre a percepção a respeito do bemestar em animais de produção, em Parauapebas, Pará, Brasil.

\begin{tabular}{ccccccc}
\hline Perguntas & F & FI & M & MI & S & SI \\
\hline 1 & $100 \%$ & $100 \%$ & $99,4 \%$ & $100 \%$ & $99,0 \%$ & $98,4 \%$ \\
2 & $18,2 \%$ & $47,6 \%$ & $55,6 \%$ & $41,4 \%$ & $79,9 \%$ & $98,4 \%$ \\
3 & $31,8 \%$ & $42,9 \%$ & $48,7 \%$ & $31,8 \%$ & $63,6 \%$ & $63,9 \%$ \\
4 & $40,9 \%$ & $71,4 \%$ & $56,5 \%$ & $55,2 \%$ & $85,5 \%$ & $73,8 \%$ \\
5 & $100 \%$ & $100 \%$ & $85,7 \%$ & $100 \%$ & $100 \%$ & $100 \%$ \\
6 & $90,9 \%$ & $81,0 \%$ & $69,5 \%$ & $51,7 \%$ & $76,4 \%$ & $70,5 \%$ \\
7 & $72,7 \%$ & $81,0 \%$ & $79,9 \%$ & $72,4 \%$ & $81,8 \%$ & $75,4 \%$ \\
\hline $\mathbf{8}$ & $\mathbf{1 8 , 2} \%$ & $\mathbf{3 3 , 3 \%}$ & $\mathbf{3 7 , 7 \%}$ & $\mathbf{5 1 , 7 \%}$ & $\mathbf{6 5 , 5 \%}$ & $\mathbf{5 7 , 4 \%}$ \\
\hline
\end{tabular}

F: Fundamental; FI: Fundamental incompleto, M: Médio; MI: Médio incompleto; S: Superior; SI: Superior incompleto 
$\mathrm{Na}$ presente pesquisa observou-se que independente da escolaridade, quase todos os entrevistados afirmam que os produtos de origem animal fazem parte de sua dieta, diariamente. Contudo, a grande maioria dos entrevistados com nível superior completo e incompleto $(79,9 \%$ e $98,4 \%$, respectivamente) sabem como são criados os animais de produção. Percebeu-se também que quanto maior o nível de escolaridade, mais as pessoas se preocupam em saber quais são os métodos utilizados para criação ou abate dos animais, destacando-se as pessoas com nível superior completo e incompleto, com 63,6 e 63,9\%, respectivamente. O maior percentual dos entrevistados com nível superior completo $(85,5 \%)$ já ouviram falar sobre bem-estar animal, com o menor percentual $(40,9 \%)$ para as pessoas com nível fundamental, o que demonstra a importância da escolaridade para que haja melhor concepção de bem-estar animal na sociedade.

Independente da escolaridade, $100 \%$ dos entrevistados acreditam que animais criados sob as normas de bem-estar originarão produtos de maior qualidade, destacando-se com menor percentual $(85,7 \%)$, as pessoas com ensino médio completo.

Embora as pessoas com nível fundamental completo e incompleto terem menor conhecimento a respeito de bem-estar animal, são as que mais informaram que pagariam mais por um produto para obter a garantia de que os animais foram criados sob condições de bemestar, com 90,9 e 81\%, respectivamente. Independente da escolaridade, a maioria dos consumidores de Parauapebas, Pará acreditam os animais de produção são submetidos a algum tipo de sofrimento durante sua o processo de criação.

Quanto maior a escolaridade, maior o conhecimento de leis que asseguram o bem-estar animal e grande parte das pessoas, independente da escolaridade, passariam a escolher produtos certificados (selos) por agências controladoras do bem-estar animal e gostariam que as redes de supermercado oferecessem produtos originados de acordo com as normas de bemestar.

Em Porto Alegre, Rio Grande do Sul, Brasil, Francisco et al. (12) observaram que um selo de garantia de qualidade é extremamente valorizado pelos consumidores daquele estado, e que, inclusive, estão dispostos a pagar mais por essa carne. Em outra pesquisa feita em Porto Alegre constatou-se que $68 \%$ das pessoas estariam dispostas a pagar até $10 \%$ a mais sobre o valor da carne, caso tivesse certificação, o que indica a preocupação em relação a fatores como origem e segurança dos alimentos (13). Em contrapartida, os consumidores de Santarém, Oeste do Pará, que embora a proteína animal faça parte da sua dieta, não possuem conhecimentos sobre BEA, e como consequência disso, não estão dispostos a pagar a mais pelos produtos com selo e não se mostram preocupados com os modos de criação dos animais (14).

Com relação à renda familiar dos consumidores, e a percepção sobre bem-estar em animais de produção (Tabela 6 ), 56,7\% possui rendimento de um a três salários mínimos, $31 \%$, de três a seis salários mínimos, $8,2 \%$, de seis a nove salários mínimos, $4,1 \%$ de 9 a 12 salários mínimos, e nenhum entrevistado ganhava acima d 12 salários mínimos. Os maiores percentuais dos entrevistados tinham renda familiar de um a três salários mínimos. Isso é, provavelmente, o reflexo do menor nível de escolaridade da maioria da população entrevistada. 
Tabela 6. Influência da renda familiar de consumidores sobre a percepção a respeito do bemestar em animais de produção, em Parauapebas, Pará, Brasil.

\begin{tabular}{cccccc}
\hline Pergunta & 1-3 salários & 3 -6 salários & 6-9 salários & 9-12 salários & 12 ou mais \\
\hline 1 & $99,5 \%$ & $99,1 \%$ & $82,1 \%$ & $100 \%$ & - \\
2 & $50 \%$ & $60,4 \%$ & $71,4 \%$ & $92,9 \%$ & - \\
3 & $46,9 \%$ & $50,9 \%$ & $67,9 \%$ & $71,4 \%$ & - \\
4 & $55,2 \%$ & $70,8 \%$ & $85,7 \%$ & $92,9 \%$ & - \\
5 & $91,8 \%$ & $94,3 \%$ & $100 \%$ & $100 \%$ & - \\
6 & $72,2 \%$ & $67,9 \%$ & $71,4 \%$ & $85,7 \%$ & - \\
7 & $76,8 \%$ & $76,4 \%$ & $89,3 \%$ & $92,9 \%$ & - \\
8 & $38,7 \%$ & $46,2 \%$ & $75 \%$ & $71,4 \%$ & - \\
9 & $87,1 \%$ & $90,6 \%$ & $96.4 \%$ & $100 \%$ & - \\
\hline $\mathbf{1 0}$ & $\mathbf{9 4 , 3 \%}$ & $\mathbf{9 7 , 2 \%}$ & $\mathbf{9 6 , 4} \%$ & $\mathbf{1 0 0 \%}$ & - \\
\hline
\end{tabular}

Grande parte dos entrevistados, de todas as rendas familiares estudadas, afirmaram que os produtos de origem animal fazem parte de sua dieta diária, porém, as pessoas que recebem salários maiores (nove a 12 salários mínimos) são as que mais conhecem sobre como os animais que originam os produtos que consomem são criados.

Observou-se também, que quanto maior a renda familiar, mais a preocupação em se conhecer quais são os métodos utilizados para criação ou abate dos animais, destacando-se as pessoas que recebem de nove a 12 salários mínimos, com $71,4 \%$ de respostas positivas a essa questão. Pessoas que recebem de um a três salários mínimos não parecem se preocupar muito com esse fato, pois apenas $46,9 \%$ delas tem essa curiosidade.

Observou-se também, na presente pesquisa, que quanto maior a renda familiar, mais as pessoas responderam que ouviram falar em bem-estar animal, com destaque para $92,9 \%$ das pessoas que recebem de nove a 12 salários mínimos.

Independente da renda familiar, a maioria dos entrevistados acreditam que animais criados sob as normas de bem-estar originarão produtos de maior qualidade, destacando-se as pessoas com renda familiar de seis a nove e de nove a 12 salários mínimos, com $100 \%$ cada. Quanto maior a renda familiar, mais as pessoas relatam que pagariam mais por um produto para obter a garantia de que os animais foram criados sob condições de bem-estar. Da mesma forma, quanto maior a renda familiar, mais as pessoas têm conhecimento sobre o fato de os animais de produção serem submetidos a algum tipo de sofrimento durante sua criação, com um percentual mais elevado de pessoas cuja renda familiar é de nove a 12 salários mínimos $(92,9 \%)$.

Também foi observado que quanto maior a renda familiar, maior o conhecimento dos entrevistados a respeito da existência de leis que asseguram o bem-estar animal. A maioria de todos os entrevistados, independente da renda familiar, escolheriam produtos certificados (selos) por agências controladoras do bem-estar animal, bem como gostariam que as redes de supermercado oferecessem produtos originados de acordo com as normas de bem-estar.

Do ponto de vista do consumidor, o preço de um produto é avaliado pela utilidade que o produto comprado lhe oferece e o custo de oportunidade, ou seja, o custo de deixar de comprar outros bens ou serviços. Há evidências claras de que o consumidor está disposto a pagar a mais por produtos de melhor qualidade ética. Entretanto, um pensamento muito comum entre os produtores é que, na realidade, quando os consumidores vão às compras, eles pensam mais no preço do que em valores éticos (15).

A preocupação quanto à compra de produtos certificados e a divulgação das marcas dentro do estabelecimento comercial foi um questionamento que a maior parte dos entrevistados alegou ser de boa relevância, visto que nos meios de comunicação e até mesmo nas grandes redes de supermercados, existe a falta de informações sobre a garantia do bem- 
estar dos animais. Esse fato poderia ser muito relevante na escolha de produtos, pois as pessoas poderiam levar em consideração a procedência e não somente o preço do produto.

Sobre a análise do qui-quadrado, observa-se na Tabela 6, que a maior parte das pessoas que responderam ao questionário consomem produtos de origem animal diariamente, logo, a pergunta 1 foi significativa para sexo e escolaridade.

As perguntas 2 e 8 foram mais significativas para renda familiar, visto que esses resultados podem estar atrelados também ao nível de escolaridade, porque geralmente pessoas com o grau de escolaridade elevado, ou, que de alguma forma, tem contato direto com o esse setor produtivo, conhecem o modo de criação dos animais, principalmente nos sistemas intensivos e de larga escala, além do bem-estar e as leis que asseguram o bom funcionamento dos processos produtivos. A pergunta 3 também foi significativamente diferente a $5 \%$ para renda, o conhecimento sobre os métodos de abate, nesse caso, não teve efeito sobre as variáveis.

Os valores nulos apresentados na Tabela 7 significam que as respostas para essas variáveis foram altamente significativas sobre as alternativas 4 e 8 , a hipótese experimental nesse caso foi aceita, pois as variáveis testadas são dependentes e o valor do qui-quadrado foi superior a 3,84. Para as demais alternativas, não houve diferença significativa em relação às variáveis, isso pode ter tido relação com o $\mathrm{N}$ amostral onde houve maior participação do sexo masculino entre 18 a 30 anos.

Tabela 7. Resultado do qui-quadrado $\left(\mathrm{X}^{2}\right)$ com as variáveis socioeconômicas.

\begin{tabular}{ccccc}
\hline \multicolumn{5}{c}{$P$ valor } \\
\hline Perguntas & Sexo & Faixa etária & Escolaridade & Renda \\
$\mathbf{1}$ & $0,007^{* *}$ & $0,632^{\mathrm{NS}}$ & $0,005^{* *}$ & - \\
$\mathbf{2}$ & $0,663^{\mathrm{NS}}$ & $0,852^{\mathrm{NS}}$ & - & $0,003^{* *}$ \\
$\mathbf{3}$ & $1,000^{\mathrm{NS}}$ & $0,848^{\mathrm{NS}}$ & $0,006^{* *}$ & $0,078^{*}$ \\
$\mathbf{4}$ & $0,431^{\mathrm{NS}}$ & $0,591^{\mathrm{NS}}$ & - & - \\
$\mathbf{5}$ & $0,121^{\mathrm{NS}}$ & $0,893^{\mathrm{NS}}$ & - & $0,256^{\mathrm{NS}}$ \\
$\mathbf{6}$ & $0,073^{*}$ & $0,125^{\mathrm{NS}}$ & $0,042^{* *}$ & $0,555^{\mathrm{NS}}$ \\
$\mathbf{7}$ & $1,000^{\mathrm{NS}}$ & $0,400^{\mathrm{NS}}$ & $0,848^{\mathrm{NS}}$ & $0,239^{\mathrm{NS}}$ \\
$\mathbf{8}$ & $0,829^{\mathrm{NS}}$ & $0,051^{* *}$ & - & $0,001^{* *}$ \\
$\mathbf{9}$ & $0,727^{\mathrm{NS}}$ & $0,812^{\mathrm{NS}}$ & $0,001^{* *}$ & $0,224^{\mathrm{NS}}$ \\
$\mathbf{1 0}$ & $0,442^{\mathrm{NS}}$ & $0,319^{\mathrm{NS}}$ & $0,014^{* *}$ & $0,560^{\mathrm{NS}}$ \\
\hline
\end{tabular}

* Significativo a 5\%; **Significativo a $1 \%$; NS: não significativo para $\mathrm{P}$ valor $>0,05$.

\section{CONCLUSÃO}

A percepção dos consumidores sobre o bem-estar animal em relação aos produtos de origem animal de Parauapebas, Pará, Brasil, é influenciada fortemente pela escolaridade e renda familiar dessas pessoas. $\mathrm{O}$ grau de instrução dos consumidores justifica quanto à escolha dos produtos com certificação de bem-estar animal, isto quando o consumidor possui uma renda mensal mais elevada, ele tem mais segurança de experimentar produtos derivados de animais criados com alto nível bem-estar, já que o maior custo desses produtos não será percebido como um risco financeiro, como ocorre para os consumidores com renda menor. A informação e o interesse pelas questões éticas compensam o risco de se experimentar tais produtos, mesmo que seja com menor frequência em relação aos produtos sem certificação.

Abreu ML, Dantas GS, Silva WC, Barbosa AVC, Silva JAR. Percepção dos consumidores de proteína animal sobre o bem-estar dos animais de produção no município de Parauapebas, Pará, Brasil. Vet. e Zootec. 2021; 28: 001-012. 


\section{REFERÊNCIAS}

1. Schaly LM, Oliveira MC, Salviano PAP, Abreu JM. Percepção do consumidor sobre bem-estar de animais de produção em Rio Verde, GO. Pubvet [Internet]. 2010 [cited 2020 Feb 21];4(38):18. Available from: http://www.pubvet.com.br/uploads/7e8feb0e14d7bece67cb14a9cc12a21a.pdf

2. Bennett EL. Is there a link between wild meat and food security? Conserv Biol. 2002;16(3):5902.

3. Molento CFM. Bem-estar e produção animal: aspectos econômicos - revisão. Arch Vet Sci. 2005;10(1):1-11. doi: http://dx.doi.org/10.5380/avs.v10i1.4078.

4. Instituto Brasileiro de Geografia e Estatística - IBGE. Síntese de indicadores sociais: uma análise das condições de vida da população brasileira: 2016. Rio de Janeiro: IBGE; 2016. (Estudos e pesquisas. Informação demográfica e socioeconômica, n. 36).

5. Levin J. Estatística aplicada a ciências humanas. São Paulo: Harbra; 1987.

6. Bonamigo A, Bonamigo CBSS, Molento CFM. Atribuições da carne de frango relevantes ao consumidor: foco no bem-estar animal. Rev Bras Zootec. 2012;41(4):1044-50. doi: $10.1590 /$ S1516-35982012000400029.

7. Raineri CR, Antonelli N, Prosdocimi Nunes BC, Simionato De Barros C, Tarazona Morales AM, Gameiro AH. Contribution to economic evaluation of systems that value animal welfare at farm. Rev Colomb Cienc Pecu [Internet]. 2012 [cited 2020 Feb 21];25:123-34. Available from: http://www.scielo.org.co/pdf/rccp/v25n1/v25n1a14.pdf

8. Pinheiro MC, Gomes FE, Lopes GN. Perfil e preferência de consumo da carne bovina na cidade de Boa Vista-Roraima (RR). Rev Agro@mbiente On-line. 2008;2(1):28-36. doi: http://dx.doi.org/10.18227/1982-8470ragro.v2i1.157.

9. Pedrazzani AS, Molento CFM, Carneiro PCF, Catilho MF. Senciência e bem-estar de peixes: uma visão de futuro do mercado consumidor. Panor Aquic [Internet]. 2007 [cited 2020 Feb 21];102:24-9. Available from: https://panoramadaaquicultura.com.br/senciencia-e-bem-estar-depeixes-uma-visao-de-futuro-do-mercado-consumidor/

10. Barcellos MD. Informação e qualidade na compra de carne bovina. Faces: Rev Admin. 2004;3(2):43-59. doi: doi.org/10.21714/1984-6975FACES2004V3N2ART35.

11. Astiz CS. Calidad de la canal y de la carne ovina y caprina y los gustos de los consumidores. Rev Bras Zootec. 2008;37(spe):143-60. doi: http://dx.doi.org/10.1590/S1516-35982008001300018.

12. Francisco DC, Nascimento VP, Loguercio AP, Camargo L. Caracterização do consumidor de carne de frango em Porto Alegre. Cienc Rural. 2007;37(1):253-8. doi: http://dx.doi.org/10.1590/S0103-84782007000100041. 
13. Velho JP, Barcellos JOJ, Lengler L, Elias SA, Oliveira TE. Disposição dos consumidores portoalegrenses à compra de carne bovina com certificação. Rev Bras Zootec. 2009;38(2):399-404. doi: doi.org/10.1590/S1516-35982009000200025.

14. Kallio JH. Animal health and animal welfare: Is it the same thing? Acta Vet Scand. 2008;50:S2. doi: https://doi.org/10.1186/1751-0147-50-S1-S2.

Recebido em: 29/06/2020

Aceito em: 18/02/2021 